targets for the reduction of serious road traffic injury using a comparable definition.

\section{LESSONS FROM TRAGEDY: AN IN-DEPTH MEDICO- LEGAL EXAMINATION OF FATAL ROAD TRANSPORT CRASHES}

\begin{abstract}
1,2 Marilyn Johnson, ${ }^{1,3,4}$ Lyndal Bugeja, ${ }^{1}$ Sjaan Koppel. 'Monash University, Australia; ${ }^{2}$ Amy Gillett Foundation, Australia; ${ }^{3}$ Coroners Court of Victoria, Australia; ${ }^{4}$ Department of Forensic Medicine, Australia
\end{abstract}

\subsection{6/injuryprev-2016-042156.188}

Background Every death on the road impacts the family, friends and relatives of the deceased as well as those people who were involved or witnessed the crash. In addition, there is a substantial economic cost of human loss. In Australia, the cost of road deaths from 2000 to 2014 is estimated at A\$458.4 million. Coronial investigations generate the most comprehensive reports of the circumstances of a fatality and while internationally coronial data has been successfully used to understand fatal road transport crashes, this data has not been used for this purpose in Australia. Methods This study is the first Australian systematic review of coronial reports for all fatal road crashes. The data is from the Australian Capital Territory for the period from 2000 to 2014. The data will be examined to determine the frequency, nature and determinants of fatal injury involving transport across all modes (e.g. cars, trucks, bikes, walking, public transport) and to understand the contributing factors, patterns and trends.

Results In total, 191 fatal road crashes occurred in the period. Analysis of the data is underway and includes identifying patterns in the factors that contribute to these crashes including: road user types involved, impaired driving (i.e. detection of alcohol and drugs), speeding, lack of care and driver distraction, single vehicle crashes, rear end crashes and right angle crashes, and vulnerable road users particularly motorcyclists, cyclists and novice drivers. The analysis will also include a review of the coronial recommendations made and the implications for road safety.

Conclusions It is anticipated that the findings from this study will provide insights into how the road transport system can be improved to achieve safety outcomes for all road user types.

\section{EXPOSURE-BASED ROAD TRAFFIC FATALITY RATES BY MODE OF TRAVEL IN FRANCE}

1,2,3 Mohamed Mouloud Haddak. 'University of Lyon, France; ${ }^{2}$ Ifsttar-Umrestte, France; ${ }^{3}$ University of Lyon, France

\subsection{6/injuryprev-2016-042156.189}

Background Travel practices are changing. Active transport modes such as walking and cycling are encouraged because they are beneficial to health and reduce pollution.

Methods We estimated the exposure-based fatality rates for road traffic crashes in France, on the basis of the ratio between the number of fatalities and exposure to road accident risk. Fatality data were obtained from the French national police database of road traffic casualties in the period 2007-2008. Exposure data was estimated from the latest national household travel survey (ENTD) which was conducted from April 2007 to April 2008. Three quantities of travel were computed for each mode of transport: (1) the number of trips, 2) the distance travelled and (3) the time spent travelling. Annual fatality rates were assessed by road user type, age and sex.
Results The fatality rates differed according to road user type, age and sex. The risk of being killed was 20 to 32 times higher for motorised two-wheeler users than for car occupants. For cyclists, the risk of being killed, both on the basis of time spent travelling and the number of trips was about 1.5 times higher than for car occupants. Risk for pedestrians compared to car occupants was similar according to time spent travelling, lower according to the number of trips and higher according to the distance travelled. People from the 17-20 and 21-29 age groups and those aged 70 and over had the highest rates. Males had higher rates than females, by a factor of between 2 and 3 .

Conclusions When exposure is taken into account, the risks for motorised two-wheeler users are extremely high compared to other types of road user. The difference between the fatality risk of cyclists and of car occupants is much smaller (1.5 times higher); besides, there is much room for improvements in cyclist safety, for instance by increasing the use of helmets and conspicuity equipment. Traffic calming could also benefit cyclists, pedestrians and perhaps moped users.

\section{BEHIND THE WHEEL: DRIVING EXPOSURE AND PARTICIPATION FROM A RANDOMISED CONTROLLED TRIAL PROGRAM FOR OLDER DRIVERS}

${ }^{1,2}$ Kristy Coxon, ${ }^{1}$ Anna Chevalier, ${ }^{1,3}$ Kate Hunter, ${ }^{4} J u l i e$ Brown, ${ }^{5}$ Elizabeth Clarke, ${ }^{1}$ Kris Rogers, ${ }^{6}$ Soufiane Boufous, ${ }^{1}$ Rebecca Ivers, 'Lisa Keay. ${ }^{1}$ The George Institute for Global Health, The University of Sydney, Sydney, NSW, Australia; ${ }^{2}$ Western Sydney University, School of Science and Health; ${ }^{3}$ The Poche Centre for Indigenous Health, Australia; ${ }^{4}$ Neuroscience Research Australia, The University of New South Wales, Sydney, NSW, Australia; ${ }^{5}$ Kolling Institute, The University of Sydney, Sydney, NSW, Australia; ${ }^{6}$ Transport and Road Safety, The University of New South Wales, Sydney, NSW, Australia

\subsection{6/injuryprev-2016-042156.190}

Background We used a randomised controlled trial, with nested process evaluation, to measure the impact of the Behind the Wheel program on driving and community participation of drivers aged 75 years and older in northwest Sydney.

Methods Driving exposure/week was measured by continuous invehicle monitoring for 12 months. The Keele Assessment of Participation (KAP), self-regulation behaviour profile and depressive symptoms were assessed at 12 months. Using intention-to-treat, generalised estimating equations modelled driving exposure, adjusting for weekly measures and ordinal regression for behaviour profiles. A logic model was built to explain program inputs, outputs and outcomes, based on relationships between process measures (program fidelity, acceptability, dose delivered and received) and program outcomes.

Results 380 drivers enrolled (mean age: $80 \pm 4$ years), 366/380 completed the study. There was no between group difference in distance driven/week over 12-months (-5.5 km, 95\% CI: $-24.5,13.5 \mathrm{~km})$, or KAP $(-0.1,95 \% \mathrm{CI}:-0.6,0.3)$. The intervention group were more engaged in self-regulation (OR: 1.6, 95\% CI: 1.1,2.3). Older drivers with low-function in the intervention group were three times more likely to report depressive symptoms (OR 3.1, 95\% CI: 1.04,9.2). Intervention participants who developed a retirement from driving plan, on average, reduced their total distance driven per week $(38 \mathrm{~km}, 95 \% \mathrm{CI}$ : $-7.5,-68.7 \mathrm{~km})$ and kilometres driven outside of daylight hours per week (7 km, 95\% CI: $-3.5,-10.4 \mathrm{~km})$. Both understanding of program content $(\beta=2.1, p=0.03,95 \% \mathrm{CI}: 0.2-4.1)$ and achieving a safe mobility plan $(\beta=3.3, \mathrm{p}=0.003,95 \% \mathrm{CI}: 1.2-$ $5.5)$ were important to engagement in self-regulation. Females 